\title{
Estudo da Reactividade de Haletos de Alquilo
}

\author{
Um Exemplo de Química Orgânica no Laboratório
}

M. ELISA S. SERRA, M. PINEIRO, D. MURTINHOE J. SEIXAS DE MELO

\section{Introdução}

Os halogenetos de alquilo são importantes intermediários em sequências sintéticas para obtenção de compostos com aplicação directa no dia a dia. Como exemplos citam-se o fármaco Prozac $(\mathbb{}$, anestésicos diversos, herbicidas, intensificadores de sabores, solventes inócuos para perfumaria, etc.

Devido à sua toxicidade ${ }^{1}$, estes compostos raramente se encontram directamente envolvidos em sistemas biológicos, com as excepções anteriormente mencionadas, pelo que o estudo dos mesmos pode parecer desadequado e impopular numa sala de aula. No entanto, muito do actual conhecimento sobre reactividade foi adquirido mediante o estudo deste tipo de compostos* A química dos halogenetos de alquilo ilustra de uma forma directa e simples, os tipos de reactividade e mecanismos que se podem encontrar em moléculas mais complexas, incluindo moléculas biológicas.
A utilidade dos halogenetos de alquilo como intermediários sintéticos resulta da grande versatilidade de uma das suas reacções mais características, a substituição nucleófilica $\left(\mathrm{S}_{\mathrm{N}}\right)$. Esta pode envolver nucleófilos (Nu:) muito diversos, transformando por sua vez os halogenetos de alquilo originais, numa grande variedade de outros compostos com diferentes grupos funcionais (ver esquema 1).

\section{Considerações Teóricas}

A grande maioria das reacções em química orgânica pode ser considerada como de natureza iónica, isto é, são devidas ao fluxo de electrões de uma molécula para outra no decurso da reacção. Os reagentes podem ser divididos, em função do seu carácter electrónico, em ricos em electrões (cedem electrões) ou pobres em electrões (recebem electrões). Os reagentes que cedem electrões, designam-se por nucleófilos, i.e., "gostam de núcleos", Nu: ou Nu:, sendo aqueles que recebem electrões, designados de electrófilos, "gostam de electrões", $E$ ou $E^{+}$. Os nucleófilos não reagem propriamente com o núcleo mas com orbitais electrónicas vazias do mesmo; se a molécula apresenta carga positiva é porque há mais protões no seu núcleo do que electrões em seu redor. Portanto a atracção e repulsão electrostática têm um papel determinante no decurso do processo reaccional. Temos então que numa reacção de tipo iónico o $\mathrm{Nu}$ : partilha, no processo de formação de uma nova ligação, um par electrónico com o $\mathrm{E}^{+}$.

As reacções de substituição nucleofilica podem processar-se por dois mecanismos distintos, que envolvem diferentes leis cinéticas: a substituição nucleofílica unimolecular $\left(\mathrm{S}_{\mathrm{N}} 1\right)$ e a substituição nucleofilica bimolecular $\left(\mathrm{S}_{\mathrm{N}} 2\right)$, figura 1 .

A substituição nucleofilica unimolecular deve o seu nome ao facto do passo mais

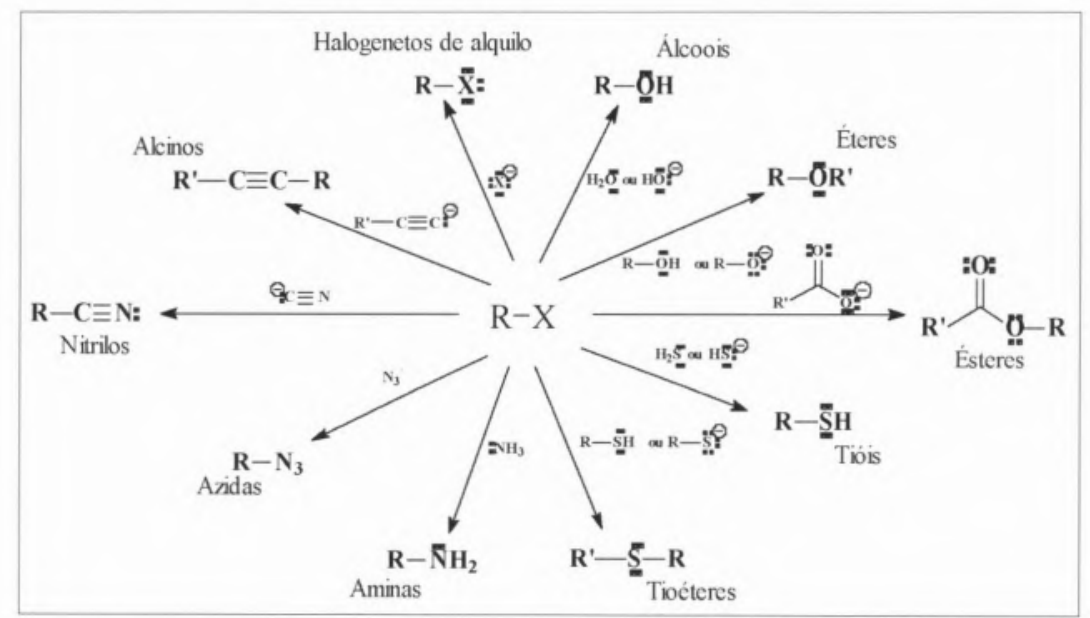

esquema 1 
lento da reacção, determinante da sua velocidade, resultar na formação de um carbocatião a partir do halogeneto de alquilo original, não envolvendo qualquer outro reagente. A expressão da lei da velocidade da reacção é v=k[R-X]. Por sua vez, na substituição nucleofílica bimolecular o passo determinante envolve a formação de um estado de transição, a partir do halogeneto de alquilo (electrófilo) e do nucleófilo, pelo que a lei da velocidade da reacção é agora dada por: $v=k[R-X][N u:]$. A ocorrência de um ou outro mecanismo depende da estabilidade dos respectivos intermediários de reacção. Na figura 2 os diagramas de energia apresentados mostram, de uma forma simplificada, a relação energiaestrutura para as reacções do tipo $\mathrm{S}_{\mathrm{N}} 1 \mathrm{e}$ $\mathrm{S}_{\mathrm{N}} 2$. Esta representação cartesiana coloca a Energia no eixo vertical (yy') e uma coordenada reaccional genérica (no caso a marcha da reacção) no eixo horizontal ( $\left.x x^{\prime}\right)$.

Os principais parâmetros, que determinam qual o tipo de mecanismo envolvido, são a estrutura da cadeia carbonada do halogeneto, o nucleófilo e o solvente.

Nas reacções $\mathrm{S}_{N} 1$, um carbocatião estável resulta de um halogeneto terciário ou secundário, sendo estes estabilizados quando o meio de reacção (solvente) tem um carácter marcadamente polar

figura 1 Mecanismos das reaç̧ôes de $\mathrm{S}_{\mathrm{N}} 1 e$ $\mathrm{S}_{\mathrm{N}} 2$. prótico, devido às pontes de hidrogénio que se estabelecem entre o solvente e o carbocatião, favorecendo assim a reacção por esta via.

Nas reacções $S_{N} 2$, o estado de transição é tanto mais estável quanto menor o volume dos substituintes do carbono que sofre a substituição, o que acontece em halogenetos de alquilo primários ou secundários; a formação deste estado de transição é favorecida pela utilização de solventes polares apróticos que por não estabelecerem pontes de hidrogénio com o nucleófilo (envolvido no passo determinante da reacção) tornam-no mais reactivo.

Outro factor importante nas reacçōes de $\mathrm{S}_{\mathrm{N}}$ resulta da sua estereoespecificidade. Na presença de compostos opticamente activos as reacções de $\mathrm{S}_{\mathrm{N}} 1$ e $\mathrm{S}_{\mathrm{N}} 2$ podem apresentar retenção de configuração, inversão de configuração ou racemização. Neste trabalho não serão consideradas as consequências estereoquímicas das reacções de $\mathrm{S}_{\mathrm{N}}$.

Pretende-se, com este trabalho, fazer uso de duas reacções de substituição nucleofilica muito conhecidas, a síntese de Williamson ${ }^{2}$ e a reacção de Finkelnstein $^{3}$. Tal possibilita o aprofundar dos conhecimentos sobre o mecanismo deste tipo de reacção, permitindo igualmente conhecer o tipo de estrutura carbonada (se primária, secundária ou terciária) dum halogeneto de alquilo desconhecido, pela simples observação do aparecimento dum precipitado no meio de reacção.

A síntese de Williamson consiste na reacção de um halogeneto de alquilo com um alcóxido para a obtenção de um éter. A reacção foi desenvolvida por Alexander Williamson em 1850 e é ainda muito utilizada na síntese de éteres assimétricos.

A reacção de Finkelstein envolve a transformação de fluoretos, cloretos ou brometos de alquilo nos correspondentes derivados iodados. Desenvolvida em 1910, a reacção é presentemente muita utilizada para a obtenção de iodetos de alquilo, que devido à elevada polarização da ligação C-I relativamente à análoga nos outros halogenetos os torna intermediários sintéticos mais reactivos.

A primeira utiliza um solvente polar prótico, favorecendo as reacções de $S_{N}$ que se processam por um mecanismo de tipo $S_{N} 1$, enquanto que a segunda faz uso de um solvente polar aprótico, favorecendo a substituição nucleofilica segundo um mecanismo do tipo $\mathrm{S}_{\mathrm{N}} 2$. Assim, quando os halogenetos de alquilo reagirem mais rapidamente nas con-

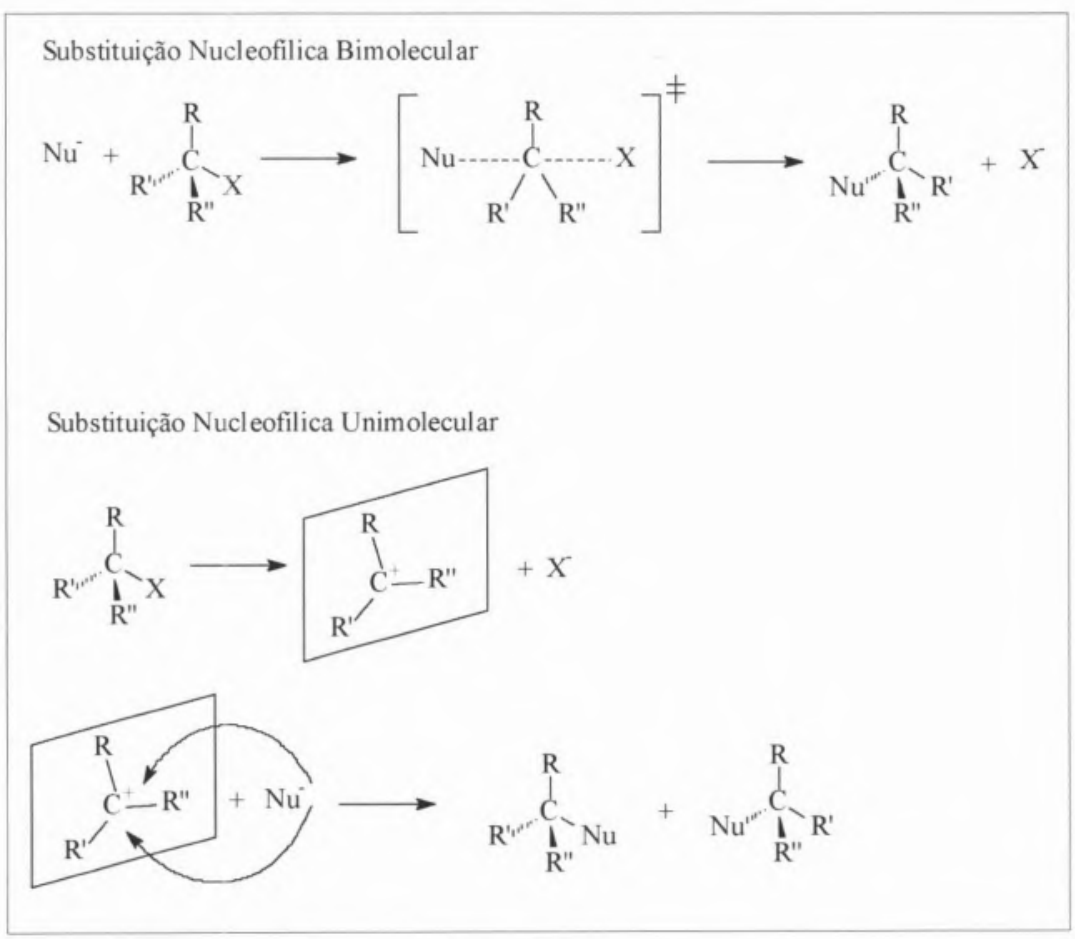




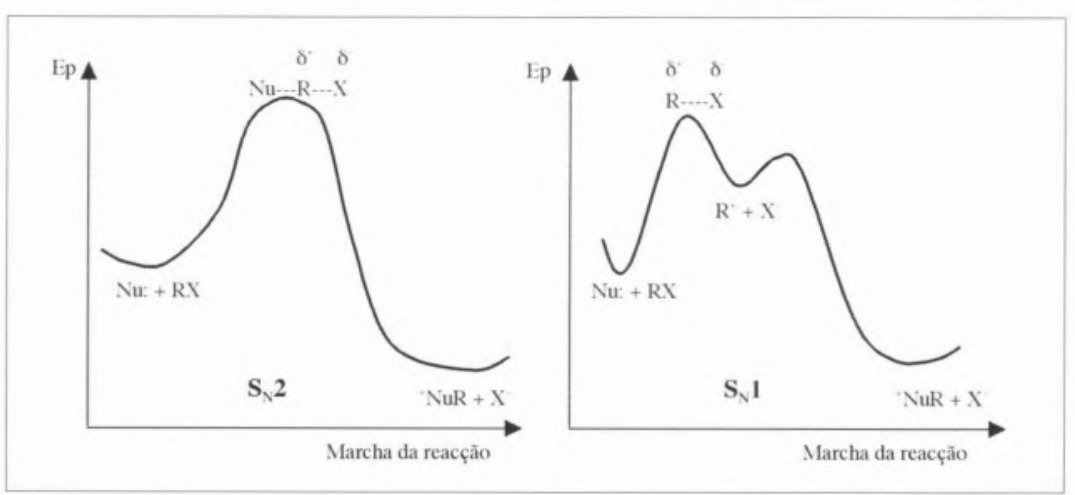

dições da reacção de Williamson será indicativo de que o mesmo é terciário ou secundário, mas aqueles que reagirem mais rapidamente nas condições da reacção de Finkelstein serão primários ou secundários.

Em ambas as reacções a ocorrência de reacção do halogeneto de alquilo é identificada pela simples observação da formação dum precipitado no meio de reaç̧ão, o que facilita em muito o objectivo pretendido.

\section{Procedimento Experimental}

\section{Síntese de Williamson vs. reacção de} Finkelstein.

Utilizando as reacções de Williamson e Finkelstein, é possível determinar se um halogeneto de alquilo reage por um mecanismo do tipo $\mathrm{S}_{\mathbb{N}} 1$ ou $\mathrm{S}_{\mathbb{N}} 2$. Serão ensaiados os seguintes halogenetos de alquilo que serão fornecidos aos alunos rotulados apenas com letras:

\section{1-clorobutano (A)}

1-bromobutano (B)

bromo-ciclo-hexano (C)

2-clorobutano (D)

2-bromobutano (E)

\section{2-cloro-2-metilpropano (F)}

\section{2-bromo-2-metilpropano (G)}

Reacção de Finkelstein (Ensaio para a identificação da ocorrência do mecanis$\left.\mathrm{mo}_{\mathrm{N}} 2\right)$ : ( $v$. esquema 2 )

Rotular sete tubos de ensaio muito bem secos (atenção: havendo humidade os ensaios não serão fidedignos) e colocar em cada um 3 gotas de um halogeneto de alquilo, rolhando rapidamente os tubos. Adicionar $1 \mathrm{ml}$ de uma solução de Nal a 15\% em acetona seca ao primeiro dos tubos. Rolhar novamente e agitar até obter uma miscibilização completa dos reagentes. Tomar nota do início da reacção e registar o tempo que decorre até ao aparecimento do precipitado. Se após 5 min. não ocorrer formação de precipitado, aquecer o tubo num banho a $50^{\circ} \mathrm{C}$. Se não se observar formação de um precipitado durante 15 min de aquecimento, considerar que não ocorreu reacção.

Repetir o procedimento com as restantes amostras fornecidas.

A reacção de Finkelstein tira partido dos cloretos e brometos de sódio serem insolúveis em acetona enquanto os iodetos são solúveis. figura 2 Representação da relação energia. estrutura para as reacções de $\mathrm{S}_{\mathrm{N}} 1$ e $\mathrm{S}_{\mathrm{N}} 2$.

Reacção de Williamson (Ensaio para a identificação da ocorrência do mecanismo $\left.S_{N} 1\right)$ : (v. esquema 3 )

Rotular sete tubos de ensaio muito bem secos e colocar em cada um 3 gotas de um halogeneto de alquilo, rolhando rapidamente os tubos. Adicionar $1 \mathrm{ml}$ de uma solução de $\mathrm{AgNO}_{3}$ a $1 \%$ em etanol ao primeiro dos tubos. Rolhar novamente e agitar até à completa mistura dos reagentes. Tomar nota do início da reacção e registar o tempo que decorre até ao aparecimento do precipitado. Se após 5 min não ocorrer formação de precipitado, aquecer o tubo num banho a $50^{\circ} \mathrm{C}$. Se durante $15 \mathrm{~min}$ de aquecimento não se observar formação de um precipitado, considerar que não ocorreu reacção.

Repetir o procedimento com as restantes amostras fornecidas.

Embora o nitrato de prata não tenha sido utilizado inicialmente por Williamson, a sua presença leva à formação do halogeneto de prata correspondente, que é insolúvel em etanol, pemitindo por simples observação concluir sobre a ocorrência da reacção.

Se 0 aluno tiver dúvidas sobre a formação de precipitado ou sobre a natureza

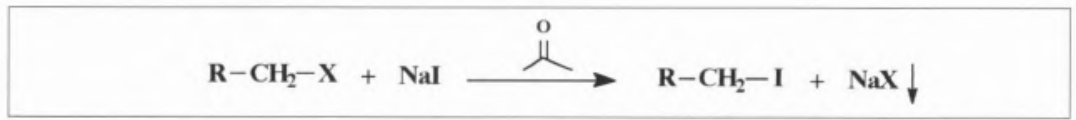

esquema 2

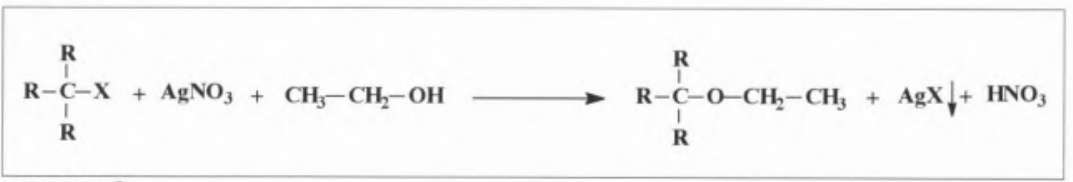

esquema 3 
Tabela 1

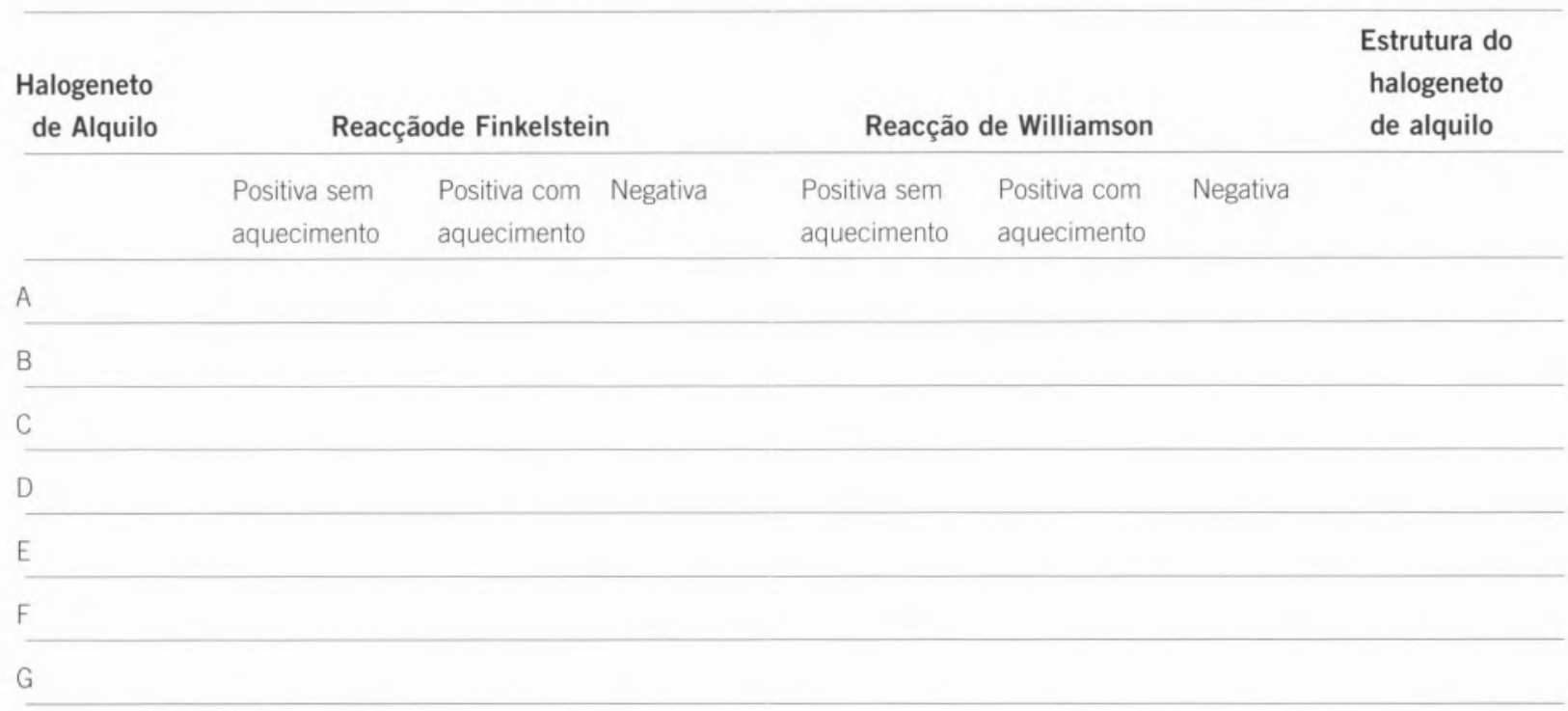

do mesmo poderá proceder aos seguintes ensaios:

Decantar o líquido de cada tubo de ensaio utilizado nos ensaios para a identificação da ocorrência do mecanismo $\mathrm{S}_{\mathrm{N}} 2$. Ao sólido resultante adicionar algumas gotas de água. A dissolução do mesmo confirma que se trata de cloreto ou brometo de sódio.

Decantar o líquido de cada tubo de ensaio utilizado nos ensaios para a identificação da ocorrência do mecanismo $\mathrm{S}_{\mathrm{N}} 1$. Ao sólido resultante adicionar algumas gotas de amoníaco a 5\%. A dissolução do mesmo confirma que se trata de cloreto de prata. Se o precipitado não dissolver, adicionar algumas gotas de amoníaco concentrado. A dissolução do mesmo confirma que se trata de brometo de prata. 0 iodeto de prata não dissolve em amoníaco

$\mathrm{AgCl}+2 \mathrm{NH}_{3} \rightarrow\left[\mathrm{Ag}\left(\mathrm{NH}_{3}\right)_{2}\right]$ (aq.) $+\mathrm{Cl}_{(\text {aq. })}$

Esquema 4

O aluno deverá elaborar uma tabela, como a que se apresenta, tabela 1. Após a análise dos resultados deverá fazer a correspondência entre as letras que identificam cada um dos halogenetos utilizados e a estrutura do mesmo: primário, secundário ou terciário.
Como trabalhos complementares poderão desenvolver-se as seguintes práticas laboratoriais:

A- Seleccionando uma das experiencias realizadas com halogenetos de alquilo terciários, transpôr a experiência para a escala quantitativa, proceder ao isolamento do éter obtido e à identificação do produto recorrendo à espectroscopia de IV, à ressonância magnética nuclear de protão, etc.

B- Seleccionando uma das experiências realizadas com halogenetos de alquilo secundários, estudar a cinética da reacção nas condições de Williamson e de Finkelstein para mostrar que na primeira a lei da velocidade da reacção é de primeira ordem e na segunda, de segunda ordem.

C- Como complemento aos conhecimentos adquiridos sobre os halogenetos de alquilo, propõe-se um trabalho sobre as reacções de eliminação que se processam pelos mecanismos E1 e E2.

\section{Notas finais}

Este trabalho é realizado na disciplina de laboratórios de Química II, do segundo ano das licenciaturas em Química e Química Industrial, no Departamento de
Química da Universidade de Coimbra. 0 trabalho revela-se estimulante e facilmente realizável em qualquer laboratório do ensino secundário, desde que tomadas as devidas precauções.

Bibliografia

J. R. Mohrig, C. N. Hammond, T. C. Morrill, D. C. Neckers, Experimental Organic Chemistry A Balanced Approach: Macroscale and Microscale, W. H. Freeman and Company, New York, 1998.

H. G. O. Becker et. al., Organikum-Química Orgânica Experimental, Fundação Calouste Gulbenkian, Lisboa, 1997.

F. A. Carey, Organic Chemistry, McGraw-Hill, New York, 2000.

K. Peter C. Vollhardt, Neil E. Schore, Organic Chemistry, W. H. Freeman and Company, New York, 1999.

G. Marc Loudon, Organic Chemistry, Oxford University Press, New York, 2002.

J. McMurry, Organic Chemistry, Brooks/Cole, Pacific Grove, USA, 2000.

R. Morrison, R. Boyd, Organic Chemistry, Fundação Calouste Gubenkian, Lisboa, 1998.

Notas

1) http://www.eurochlor.org

2) Williamson, A. Philosophical Magazine 37 (1850) 350.

3) Finkelstein, H. Ber. Deut. Chem. Ges. 43 (1910) 1528. 